\title{
Radical Recombinations in Acetylene-Air Flames
}

\author{
P. J. Th. Zeegers and C. Th. J. Alkemade \\ Ihysics Laboratory of the State University, Bijlhouwerstraat 6 , Utrecht, Netherlands
}

(Received January 1965)

\begin{abstract}
In this paper an analysis is given of the behaviour of excess radical concentrations, $\mathrm{H}, \mathrm{OH}$ and $\mathrm{O}$ as a function of height above the reaction zone in premixed acetylene-air flames at $2-200^{\circ}$ to $2400^{\circ} \mathrm{K}$ and 1 atmosphere pressure. The intensity was measured of the $\mathrm{Li}$ vesonance' line which is related to the $\mathrm{H}$ concentration through the lithium-water equilibrium. The $\mathrm{OH}$ concentration was measured by absorption of the $(0,0)$ band of $\mathrm{OH}$ at 3064 A. The $\mathrm{H}, \mathrm{OH}$ and $\mathrm{O}$ concentrations are related to one another by rapid, binary exchange reactions with stable flame molecules. A rather elaborate but complete mathematical expression is derived. which takes into account (i) the four recombination reactions $\mathrm{H}+\mathrm{H}, \mathrm{H}+\mathrm{OH}, \mathrm{O}+\mathrm{O}$ and $\mathrm{CO}+\mathrm{O}$, and the reverse reactions; (ii) the variation of stable molecule concentrations dut to radical recombination; (iii) the effect of varying temperature on the flame equilibria. The experimental results were found to be consistent with theory. By making use of some additional literalure data it appeared that the decay of excess radicals in our flames is mainlv governed by $\mathrm{H}+\mathrm{OH}$ and (to a less extent) $\mathrm{CO}+\mathrm{O}$ recombination. The binary rate constant

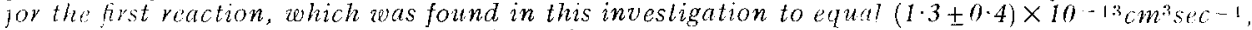
agre's with literature data obtained in hydrogen flames. As a side result of this investigation the dissociation energy of $\mathrm{LiOH}$ was found to be $110 \pm 5 \mathrm{kcal}$ mol which narrows the uncertainty in this quantity when combined with two other values reported in the literature.
\end{abstract}

\section{Introduction}

THE burnt gas mixture of a hydrocarbon-air flame contains $\mathrm{H}, \mathrm{OH}$ and $\mathrm{O}$ radicals as minor species. The concentrations of these radicals usually exceed equilibrium values for a few milliseconds after leaving the reaction zone. The radical concentrations will approach equilibrium gradually by ternary recombination reactions ${ }^{1-3}$. A study of the behaviour of the radicals is not only of interest as a subject in itself, but also because it may affect the excitation of metal atoms and hydroxyl radicals (chemiluminescence $)^{i-6}$, the ionization of alkali metals (chemiionization $)^{i, 8}$, the dissociation of metal compounds, the continuous flame background emission and the flame temperature.

In particular, this paper will be concerned with the occurrence and decay of excess $\mathrm{H}, \mathrm{OH}$ and $O$ radicals above the reaction zone of premixed acetylene-air flames burning at one atmosphere. These flames have been extensively studied in our Department ${ }^{9-11}$ and the measurements described here may contribute to the understanding of the physical and physicochemical effects in this type of flame.

It should be noted that the kinetics of radical recombination of the type

$$
\mathrm{OH}(\text { or } \mathrm{H})+\mathrm{H}+\mathrm{M} \rightarrow \mathrm{H}_{22} \mathrm{O}\left(\text { or } \mathrm{H}_{12}\right)+\mathrm{M}
$$

where $\mathrm{M}$ is a flame gas molecule carrying off the reaction energy released, have been studied extensively in hydrogen-oxygen-nitrogen flames ${ }^{12-15}$. However, the situation in hydrocarbon flames, as studied by us, is considerably complicated by the following factors ${ }^{1}$ :

(i) the decay of excess $\mathrm{O}$ radicals through the recombination reactions $\mathrm{CO}+\mathrm{O} \longrightarrow \mathrm{CO}_{2}$ and $\mathrm{O}+\mathrm{O} \longrightarrow \mathrm{O}_{2}$ is linked up with the decay of the $\mathrm{H}$ and $\mathrm{OH}$ radicals in consequence of the existence of rapid, balanced reactions involving these three radicals and the stable flame molecules;

(ii) the molecular $\mathrm{H}_{2}, \mathrm{O}_{2}$ and $\mathrm{CO}$ concentrations cannot always be assumed largely to exceed the radical concentrations in our flames; so their values may be affected markedly by the decay of excess radicals;

(iii) the excess value of radical concentrations does not always exceed their equilibrium value to such a large extent as in hydrogen flarnes; so we are not allowed to neglect a priori the reverse dissociating reactions; 
(iv) moreover, in some of the flames investigated a noticeable initial rise in temperature with increasing distance from the reaction zone was observed. The associated effect on the bulk flame gas composition and on the rate of the reverse dissociating reactions had to be taken into account.

In what follows these complications will be dealt with explicitly.

\section{Theoretical Analysis}

When the $\mathrm{H}$ and $\mathrm{OH}$ concentrations exceed the equilibrium value, these excess concentrations will decrease from the reaction zone downstream. The equilibrium concentration is approached, but never reached, if the equilibrium concentration varies continually with varying temperature downstream. The relaxation of the $\mathrm{H}$ and $\mathrm{OH}$ equilibria in the acetylene-air flame investigated at one atmosphere may, roughly, be described by a relaxation time of the order $2 \cdot 5$ msec.

The approach to flame equilibrium will now be investigated more specifically.

The following ternary recombination reactions and their reverse reactions have to be taken into account:

$$
\begin{aligned}
& \mathrm{H}+\mathrm{H}+\mathrm{M} \underset{k_{-1}}{\stackrel{k_{1}}{\rightleftarrows}} \mathrm{H}_{2}+\mathrm{M} \ldots[\mathrm{I}] \quad K_{1}=k_{1} / k_{-1} \\
& \mathrm{H}+\mathrm{OH}+\mathrm{M} \underset{k_{-2}}{\stackrel{k_{2}}{\rightleftarrows}} \mathrm{H}_{2} \mathrm{O}+\mathrm{M} \ldots[\mathrm{II}] \quad K_{2}=k_{2} / k_{-2} \\
& \begin{array}{c}
\mathrm{CO}+\mathrm{O}+\mathrm{M} \underset{k_{-3}}{\stackrel{k_{3}}{\rightleftarrows}} \mathrm{CO}_{2}+\mathrm{M} \ldots[\mathrm{III}] \quad K_{3}=k_{3} / k_{-3} \\
\mathrm{O}+\mathrm{O}+\mathrm{M} \underset{k_{-4}}{\stackrel{k_{4}}{\rightleftarrows}} \mathrm{O}_{2}+\mathrm{M} \ldots[\mathrm{IV}] \quad K_{4}=k_{4} / k_{-4}
\end{array} \\
& \begin{array}{c}
\mathrm{CO}+\mathrm{O}+\mathrm{M} \underset{k_{-3}}{\stackrel{k_{3}}{\rightleftarrows}} \mathrm{CO}_{2}+\mathrm{M} \ldots[\mathrm{III}] \quad K_{3}=k_{3} / k_{-3} \\
\mathrm{O}+\mathrm{O}+\mathrm{M} \underset{k_{-4}}{\stackrel{k_{4}}{\rightleftarrows}} \mathrm{O}_{2}+\mathrm{M} \ldots[\mathrm{IV}] \quad K_{4}=k_{4} / k_{-4}
\end{array}
\end{aligned}
$$

Equations 5 to 8 give four independent relations between radicals and stable molecules. All other relations between flame constituents may be found by some combination of these equations. It has been assumed that ali flame particles have equal efficiency as third bodies. Here only a short survey of the method of solving $-\mathrm{d}[\mathrm{H}] / \mathrm{d} t$ and $-\mathrm{d}[\mathrm{OH}] / \mathrm{d} t$ is given. A detailed derivation will be found elsewhere ${ }^{17}$. The net rate of change of the $\mathbf{H}$-radical concentration is given by

$$
\begin{array}{r}
-(\mathrm{d}[\mathrm{H}] / \mathrm{d} t)=2 k_{1}[\mathrm{M}][\mathrm{H}]^{2}-2 k_{-1}[\mathrm{M}]\left[\mathrm{H}_{2}\right] \\
+k_{2}[\mathrm{M}][\mathrm{H}][\mathrm{OH}]-k_{-2}[\mathrm{M}]\left[\mathrm{H}_{2} \mathrm{O}\right] \\
-(\mathrm{d}[\mathrm{H}] / \mathrm{d} t)_{\mathrm{V}}-(\mathrm{d}[\mathrm{H}] / \mathrm{d} t)_{\mathrm{VI}} \\
-\mathrm{d}[\mathrm{H}] / \mathrm{d} t)_{\mathrm{VII}}-(\mathrm{d}[\mathrm{H}] / \mathrm{d} t)_{\mathrm{VIII}}
\end{array}
$$

in which $(\mathrm{d}[\mathrm{H}] / \mathrm{d} t)_{\mathrm{v}}$, etc. to $(\mathrm{d}[\mathrm{H}] / \mathrm{d} t)_{\mathrm{vIII}}$ stand for the rate of change of $[\mathrm{H}]$ as a result of a shift in the specific reaction equilibria $\mathrm{V}$, etc. to VIII. Similar expressions can be written for: $-\mathrm{d}[\mathrm{OH}] / \mathrm{d} t, \quad-\mathrm{d}[\mathrm{O}] / \mathrm{d} t, \quad-\mathrm{d}\left[\mathrm{H}_{2}\right] / \mathrm{d} t$, $-\mathrm{d}\left[\mathrm{O}_{2}\right] / \mathrm{d} t$ and $-\mathrm{d}[\mathrm{CO}] / \mathrm{d} t$.

Since $\mathrm{H}$ atoms play a part in each equilibrated reaction, it is possible to express the specific rates of change of all the other particle concentrations in terms of the specific rate of change of the $\mathrm{H}$ concentration.

as well as the equilibrated binary exchange reactions:

$$
\begin{aligned}
& \mathrm{H}_{2}+\mathrm{OH} \rightleftarrows \mathrm{H}+\mathrm{H}_{2} \mathrm{O} \ldots .[\mathrm{V}] \quad K_{5}=\left[\mathrm{H}_{2} \mathrm{O}\right][\mathrm{H}] /\left[\mathrm{H}_{2}\right][\mathrm{OH}] \\
& \mathrm{H}_{2}+\mathrm{O} \rightleftarrows \mathrm{H}+\mathrm{OH} \ldots[\mathrm{VI}] \quad K_{6}=[\mathrm{H}][\mathrm{OH}] /\left[\mathrm{H}_{2}\right][\mathrm{O}] \\
& \left.\mathrm{O}_{2}+\mathrm{H} \longleftrightarrow \mathrm{O}+\mathrm{OH} \ldots . . \mathrm{VII}\right] \quad K_{7}=[\mathrm{O}][\mathrm{OH}] /\left[\mathrm{O}_{2}\right][\mathrm{H}] \\
& \mathrm{CO}+\mathrm{OH} \rightleftarrows \mathrm{H}+\mathrm{CO}_{2} \ldots \text { [VIII] } K_{8}=\left[\mathrm{CO}_{2}\right][\mathrm{H}] /[\mathrm{CO}][\mathrm{OH}]
\end{aligned}
$$


Four other relations may be derived from the equilibria $\mathrm{V}$ to VIII at the prevailing flame temperature, which are of the type:

$\mathrm{d} \ln [\mathrm{H}] / \mathrm{d} t=\mathrm{d} \ln [\mathrm{OH}] / \mathrm{d} t+\mathrm{d} \ln \left[\mathrm{H}_{2}\right] / \mathrm{d} t$

$$
-\mathrm{d} \ln \left[\mathrm{H}_{2} \mathrm{O}\right] / \mathrm{d} t+\mathrm{d} \ln K_{5} / \mathrm{d} t
$$

The terms $d \ln \left[\mathrm{H}_{2} \mathrm{O}\right] / \mathrm{d} t$ and $\mathrm{d} \ln \left[\mathrm{CO}_{2}\right] / \mathrm{d} t$ occurring in these four equations may be disregarded (see Figures 3 and 4). By using $\mathrm{d} \ln K / \mathrm{d} t=W \star / R T^{2} \quad(W \star \quad$ stands for the reaction enthalpy) we find

$$
\mathrm{d} \ln K / \mathrm{d} t=-(W \star / R)\left(\mathrm{d} T^{-1} / \mathrm{d} t\right)
$$

After solving for $\mathrm{d}[\mathrm{H}] / \mathrm{d} t$ and $\mathrm{d}[\mathrm{OH}] / \mathrm{d} t$ we get :

$$
\begin{array}{r}
\left.-A \mathrm{~d}|\mathrm{H}| / \mathrm{d} t=\{[\mathrm{H}] \mid \mathrm{OH}]-\left[\mathrm{H}_{2} \mathrm{O}\right] / K_{2}\right\} E B_{\mathrm{H}} \\
+C_{\mathrm{H}}[\mathrm{H}] \mathrm{d} T^{-1} / \mathrm{d} t \\
\ldots \ldots[10]
\end{array}
$$

and

$$
\begin{array}{r}
-A \mathrm{~d}[\mathrm{OH}] / \mathrm{d} t=\left\{[\mathrm{H}][\mathrm{OH}]-\left[\mathrm{H}_{2} \mathrm{O}\right] / K_{2}\right\} E B_{\mathrm{OH}} \\
-C_{\mathrm{OH}}[\mathrm{OH}] \mathrm{d} T^{-1} / \mathrm{d} t \\
\ldots \ldots[11]
\end{array}
$$

Here the factors $A, B_{\mathrm{H}}, B_{\mathrm{OH}}, C_{\mathrm{H}}$ and $C_{\mathrm{OH}}$ contain (among other things) the equilibrium constants and the concentrations of flame molecules and radicals, and are defined by:

$$
\begin{aligned}
& A=4 \alpha^{2} \beta^{2} / p q+\alpha\left(4+\beta / q+\beta^{2} / q K_{5}\right) \\
& +(r \gamma+1)\left(p / \beta+K_{6}\right) / \alpha \\
& +4(r \gamma+1)(\beta / q+1)+K_{0} \\
& B_{\mathrm{H}}=\alpha(4+12 \beta / q)+(r \gamma+1) 2 p / \alpha \beta+K_{6} \\
& C_{\mathrm{H}}=\left(-W_{i}^{\star}+W_{6}^{\star}+W_{7}^{\star}+3 W_{8}^{\star}\right) 2 \beta \gamma r / q R \\
& \left.+\left(2 W_{5}^{\star}+W_{6}^{\star}\right) 2 \beta / q R\right) \\
& +\left(-W_{5}^{\star}+W_{b}^{\star}+2 W_{8}^{\star}\right) 2 \gamma \gamma / R \\
& B_{\mathrm{OH}}=4 x \beta^{2} / q K_{5}+K_{6}+2 K_{6} / \alpha+2 \gamma K_{6} \gamma / \alpha \\
& C_{\mathrm{OH}}=\left(W_{5}^{\star}-W_{6}^{\star}-W_{\overline{7}}^{\star}-W_{8}^{\star}\right) 2 \beta \gamma r / q R \\
& +\left(W_{5}^{\star}-W_{6}^{\star}-W_{7}^{\star}\right) 3 \alpha \beta / q R \\
& +\left(W^{\star}-W_{6}^{\star}\right) 2 \gamma \gamma / R
\end{aligned}
$$

where

$\alpha=[\mathrm{H}] /\left[\mathrm{H}_{2}\right], \beta=\left[\mathrm{H}_{2} \mathrm{O}\right] /\left[\mathrm{H}_{2}\right], \gamma=\left[\mathrm{CO}_{2}\right] /\left[\mathrm{H}_{2} \mathrm{O}\right]$, $p=K_{5} K_{6}, q=K_{5} K_{7}, \quad r=K_{5} / K_{8}, R$ is the gas constant and $W_{5}^{\star}, W_{6}^{\star}, W_{\pi}^{\star}$ and $W_{8}^{\star}$ stand for the reaction enthalpies of the binary exchange reactions $V$, VI, VII, VIII, respectively. The expression for $C_{\mathrm{H}}$ and $C_{\mathrm{OH}}$, in which terms of minor importance have been disregarded, are accurate within 20 per cent for our flames.

$E$ stands for $[M] \times$

$\left\{k_{2}+k_{1} K_{5}\left[\mathrm{H}_{2}{ }^{\left[\mathrm{H}_{2}\right]}\right]+k_{3} \frac{K_{5}}{K_{6} K_{8}}\left[\overline{\left.\mathrm{H}_{2} \mathrm{O}\right]}+k_{4} \frac{K_{5}}{K_{6}} \frac{K_{7}}{\left[\mathrm{CO}_{2}\right]}\right]\right.$

It should be noted that $K_{2}$ occurs in equations 10 and 11 as the only equilibrium constant of a non-balanced reaction II. The factors $A, B_{\mathrm{H}}$, $B_{\mathrm{OH}}, C_{\mathrm{H}}$ and $C_{\mathrm{OH}}$ contain the equilibrium constants of balanced reactions and the concentrations of major stable species and of atomic hydrogen, whereas the factor $E$ includes, besides these quantities, also the rate constants of the reactions I, II, III and IV.

From formulas 10 and 11 by eliminating $E$ one gets

$$
\begin{array}{r}
A \mathrm{~d}[\mathrm{H}] / \mathrm{d} t+C_{\mathrm{H}}[\mathrm{H}] \mathrm{d} T^{-1} / \mathrm{d} t \\
=\left\{A \mathrm{~d}[\mathrm{OH}] / \mathrm{d} t-C_{\mathrm{OH}}[\mathrm{OH}] \mathrm{d} T^{-1} / \mathrm{d} t\right\} B_{\mathrm{H}} / B_{\mathrm{OH}} \\
\ldots .[12]
\end{array}
$$

This equation, which relates $\mathrm{d}[\mathrm{H}] / \mathrm{d} t$ to $\mathrm{d}[\mathrm{OH}] / \mathrm{d} t$, may be used for checking the internal consistency of the theoretical assumptions from the measured decay of the $\mathrm{H}$ and $\mathrm{OH}$ radical concentrations, without knowledge of the value of the radical recombination rate constants.

\section{Experimental}

Acetylene gas and air supplied from high pressure tanks were metered and mixed in a separate mixing chamber and were led into a brass Meker-type burner. The height of the primary combustion cones amounted to about $3 \mathrm{~mm}$. Before entering the burner the air flow was led under pressure into a spray chamber in order to introduce the test solutions into the flame as a fine haze as usual ${ }^{16}$. The cylindrical, laminar flame was surrounded by a mantle of flowing cold nitrogen gas which prevented secondary combustion by indrawn air at the flame border up to about $8 \mathrm{~cm}$ from the reaction zone. The favourable effect of this mantle was checked by measuring the ultra-violet $\mathrm{OH}$ emission as a function of the off-axis distance. After correction for the variation of flame-depth with off-axis distance, the $\mathrm{OH}$ emission was 


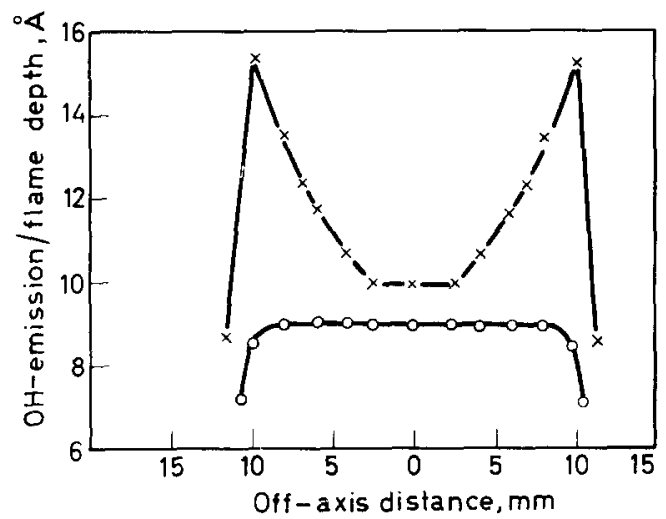

Figure 1. Shielding effect of $\mathrm{N}_{2}$ mantle. The $\mathrm{OH}$ emission measured with and without $\mathrm{N}_{2}$ mantle is indicated by o and $\mathrm{x}$, respectively. The height of measurement is $3 \mathrm{~cm}$ downstream from the reaction zone, corresponding to a time of $3 \mathrm{msec}$

indeed found to be constant (see Figure 1). It is seen from this figure that the flame diameter amounts to about $20 \mathrm{~mm}$. The flame diameter varies with height by 20 per cent at the most. All our measurements were corrected for this variation. The thickness of the shielding nitrogen mantle was $10 \mathrm{~mm}$. In order to obtain a good definition of the height of measuring in the flame, a horizontal image of the flame was projected on to the vertical entrance slit of the monochromator by means of two plane mirrors which deflected the light beam by $90^{\circ}$ in a horizontal and vertical plane respectively. The height of measuring could be varied by shifting the burner along a vertical axis.

Diaphragms were inserted such that only a small pencil of flame light intersecting the flame axis at right angles was observed. The cross-sectional area of this pencil was about $2 \mathrm{~mm}^{2}$. The spectral wavelength interval studied was selected by means of a simple Zeiss monochromator provided with a quartz prism.

In the emission measurements a periodic light-chopper with modulation frequency $50 \mathrm{c} / \mathrm{s}$ was placed between flame and monochromator. The a.c. output current of an RCA 1P28 photomultiplier tube was amplified and measured by an electronic synchronous detector as described elsewhere ${ }^{9,16}$. The linearity of the measuring device was checked.

In the absorption measurements the lightchopper was placed between the background light source and the flame under analysis. In this way the (d.c.) emission of the analysis flame was prevented from interfering with the absorption measurements. Absorption measurements were, in particular, used for the determination of the relative concentration of groundstate $\mathrm{OH}$ radicals. Since the absorptivities of the $\mathrm{OH}$ resonance bands at $3064 \AA$ are only small and since our monochromator was certainly not capable of resolving the band structure, we used an auxiliary acetylene flame that emitted the same bands as a specific background source. By making the background radiation pass the analysis flame twice (at the same spot in the flame; see Figure 2), absorption factors ranging from 15 to 40 per cent could be obtained, depending on the conditions in the analysis flame.

\section{Flame characteristics}

The measurements were carried out with three acetylene-air flames of typically different quantitative gas composition and temperature (sec Table 1).

Table 1. Characteristics of the flames investigated

\begin{tabular}{cccccc}
\hline $\begin{array}{c}\text { Flame } \\
\text { no. }\end{array}$ & $\begin{array}{c}\text { Acetylene } \\
\text { supply } \\
\text { l./min }\end{array}$ & $\begin{array}{c}\text { Air } \\
\text { supply } \\
\text { l./min }\end{array}$ & $\begin{array}{c}\text { Rise } \\
\text { velocity } \\
\text { m/sec }\end{array}$ & $\begin{array}{c}\text { Temp. } \\
\text { calc. } \\
\text { 'K }\end{array}$ & $\begin{array}{c}\text { Max. } \\
\text { temp. } \\
\text { meas. } \\
\text { "K }\end{array}$ \\
\hline 1 & 1.68 & 20.6 & 13.5 & 2498 & 2307 \\
2 & 2.18 & 20.6 & 10.7 & 2577 & 2410 \\
3 & 4.5 & 20.6 & 10.6 & - & 2310 \\
\hline
\end{tabular}

The rise velocity $v$ of the burnt flame gases was measured by photographing the tracks of small aluminium particles carried by the gas, as described elsewhere ${ }^{11}$. The height of measurement in the flame, $h$, is related to the rise-time taken by the observed flame element, $t$, by the equation $h=v t$.

The theoretical equilibrium flame temperature was calculated from the known gas and air supplies by means of a binary electronic computer, taking into account as dissociation products, in equilibrium, $\mathrm{H}, \mathrm{OH}$ and $\mathrm{O}$ radicals, but not $\mathrm{CH}$ and $\mathrm{C}_{2}$ radicals*. Flame No. 3 is a typical fuel-rich flame which did show the $\mathrm{CH}$ and $\mathrm{C}_{2}$ bands in the spectrum of the burnt gases above the reaction zone. For this flame the equilibrium value of the temperature was not calculated. 


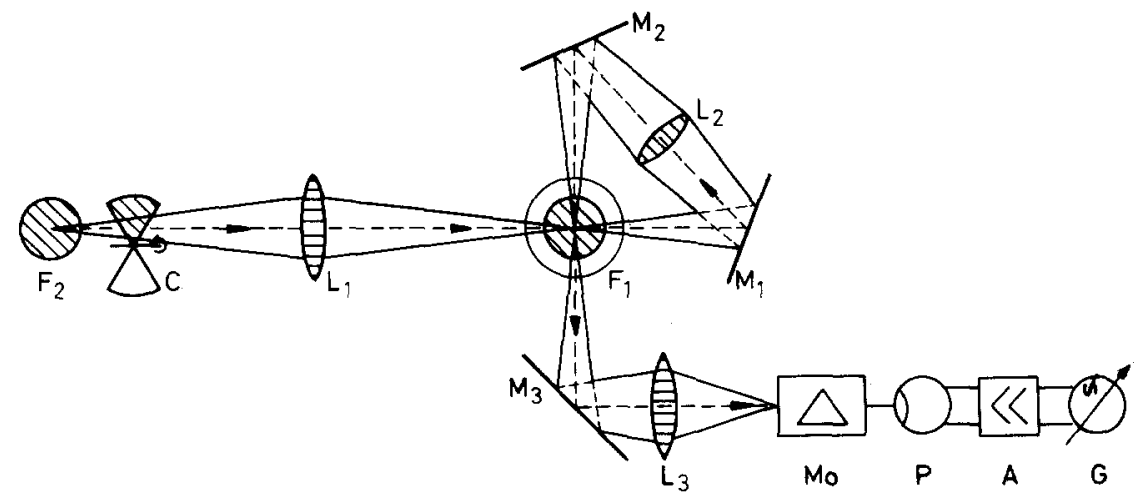

Figure 2. Experimental set-up for absorption mesurements in order to determine the $\mathrm{OH}$ radical concentration. The radiation of an anxiliary acetylene-air flame $\left(F_{2}\right)$ is interrupted by a periodic mechanical light-chopper $(C)$ and focused with a quartz lens $\left(L_{1}\right)$ on the vertical axis of the acetylene-air flame with $\mathrm{N}_{2}$ mantle $\left(F_{1}\right)$ in which the $\mathrm{OH}$ concentration has to be measured. By means of two plane mirrors $\left(M_{1}\right.$ and $\left.M_{2}\right)$ and a quartz lens $\left(L_{2}\right)$ the radiation of $F_{2}$ is allowed to pass twice through the analysis flame $F_{1}$. The $u v$. radiation passing the monochromator (Mo) is detected by an R.C.A. $1 P-28$ photomultiplier tube $(P)$. The a.c. output current of $P$ is amplified $(A)$ and measured by a synchronous rectifier in combination with i d.c. ammeter $(G)$

The actual flame temperature was measured visually by the sodium line reversal method, and appeared to vary with rise-time (see Figure 3). The maximum values found were lower than the theoretical adiabatic flame temperature because of heat losses ${ }^{9}$. The initial increase of flame temperature is to be explained by the gradual recombination of excess $\mathrm{H}, \mathrm{OH}$ and $O$ radicals, which releases some additional heat (see below). The relative variation of flame temperature with rise-time could be determined with greater precision by measuring the emission of the Na- $D$ doublet as a function of risetime after correction for the (slight) variation in the concentration of sodium ground state atoms and in flame thickness. It has been shown ${ }^{5}$ that with our flame conditions the $\mathrm{Na}-\mathrm{D}$ line is free from chemiluminescence effects, so the measured excitation temperature of sodium is equal to the true translational temperature of the flame gases.

In addition the equilibrium flame gas composition was calculated as a function of risetime, starting from the temperatures measured and the known fuel-gas and air supplies with the aid of the computer. Figure 3 summarizes the results for the major stable species only. Figures 4 and 5 show the equilibrium concen- trations of $\mathrm{H}$ and $\mathrm{OH}$, which were calculated at the actual flame temperature as a function of height. In all our measurements with metal resonance lines self-absorption was avoided by choosing sufficiently low solution concentrations. Ionization, which may become noticeable at these low concentrations, was suppressed by adding an easily ionizable element in excess as electron donor to the test solution (cf. ref. 16).

\section{The Observed Decay of $\mathrm{H}$ and $\mathrm{OH}$ Concentration with Time}

\section{The $\mathrm{H}$ radical concentration}

The determination of $[\mathrm{H}]$ is based upon the partial equilibrium of the fast, binary reaction of $\mathrm{Li}$ atoms with water according to ${ }^{18,19}$

$$
\mathrm{Li}+\mathrm{H}_{2} \mathrm{O} \rightleftarrows \mathrm{LiOH}+\mathrm{H} \ldots .
$$

with

$$
K_{9}(T)=[\mathrm{LiOH}][\mathrm{H}] /[\mathrm{Li}]\left[\mathrm{H}_{2} \mathrm{O}\right]
$$

Assuming that $K_{9}(T)$ is of order unity and that $\left[\mathrm{H}_{2} \mathrm{O}\right] /[\mathrm{H}]$ is much larger than unity, and considering $[\mathrm{Li}]+[\mathrm{LiOH}]=\overline{[\mathrm{Li}}]$, we may write

$$
[\mathrm{H}]=K_{9}(T)\left[\mathrm{H}_{2} \mathrm{O}\right][\mathrm{Li}] / \overline{\mathrm{Li}}
$$

When 40 p.p.m. lithium chloride solutions are used, with 2000 p.p.m. potassium chloride added as electron donor element for suppressing 


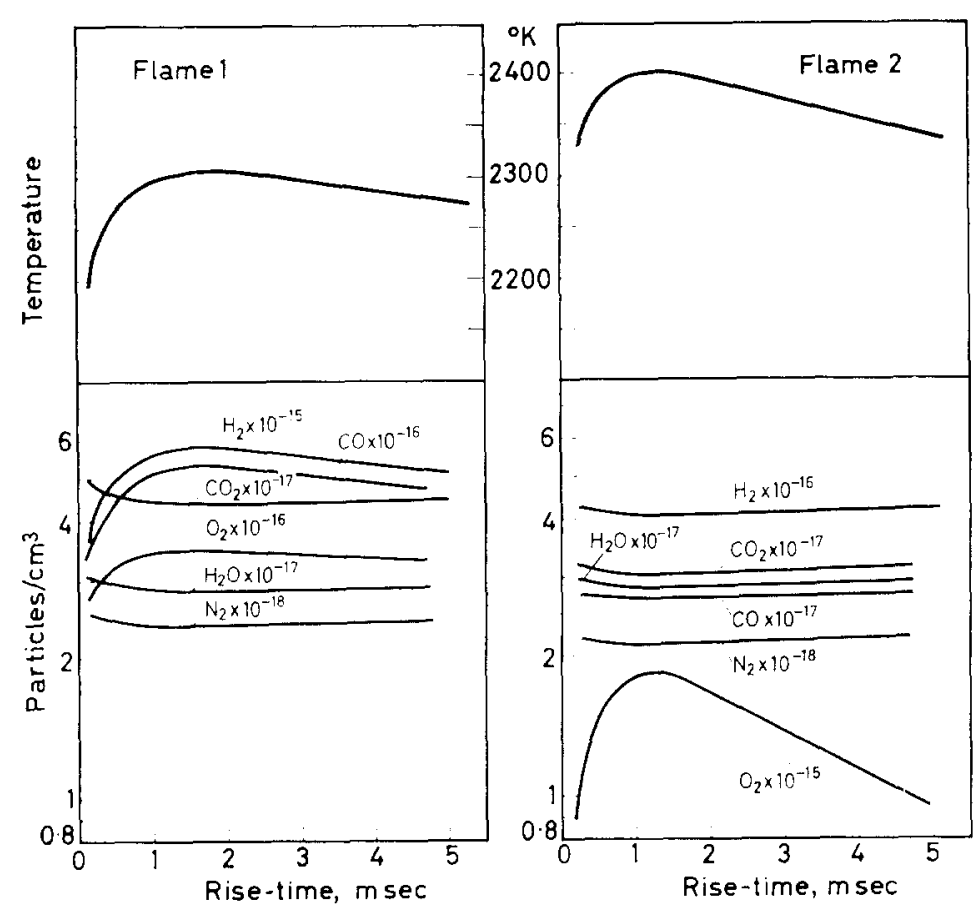

Figure 3. Temperature and equilibrium concentrations of the stable flame species, calculated at the actual flame temperature, as functions of time after leaving the reaction zone. for flames Nos. 1 and 2, respectively

lithium ionization, it may be assumed that [Ti] is, virtually, independent of rise-time in our cylindrical flame (cf. also ref. 10). Diffusion effects and formation of $\mathrm{LiCl}$ molecules in our flames may be disregarded. Since, moreover, water vapour is one of the major stable species in the flame, its concentration may be assumed to equal the equilibrium value which appears to be virtually independent of rise-time (see Figure 3). So we have $[\mathrm{H}] \propto K_{9}(T)[\mathrm{Li}]$ in a given flame.

Measurement of the (thermal) atomic lithium emission at $6708 \AA$, after correction for its variation with temperature as a function of rise-time, will yield the $H$ radical concentration as a function of rise-time in relative measure. With the low lithium atom concentrations used in these measurements, correction for selfabsorption of the resonance line appeared to be unnecessary. The behaviour of the lithium atom content as a function of height, derived from the emission measurements, was found to agree with the results obtained by absorption measure- ments, in which a flame coloured by $\mathrm{Li}$ atoms was used as background source. The same setup as that shown in Figure 2 was used in these absorption measurements. In these measurements a higher concentration of $\mathrm{Li}$ in the test flame was used.

A complication arises since allowance should be made not only for the effect of varying temperature on $\mathrm{Li}$ emission, according to the Boltzmann formula, but also for its effect on the value of the equilibrium constant $K_{9}(T)$. We calculated the variation of $K_{9}(T)$ with temperature from measurements of the ratio $[\mathrm{LiOH}] /[\mathrm{Li}]$ in acetylene-air flames at various temperatures; these were performed far enough away from the reaction zone for the flame gas composition to be assumed to be virtually equilibrated. From these measurements we found the reaction enthalpy $W_{\mathrm{Li}}^{\star}$ of the $\mathrm{Li}-\mathrm{H}_{2} \mathrm{O}$ reaction equal to $14 \pm 2 \mathrm{kcal} / \mathrm{mol}$. This value was used to correct $K_{,}(T)$ for variations in temperature according to

$$
\mathrm{d} \ln K_{\mathrm{g}}(T) / \mathrm{d} T=W_{\mathrm{I} . \mathrm{i}}^{\star} / R T^{2}
$$




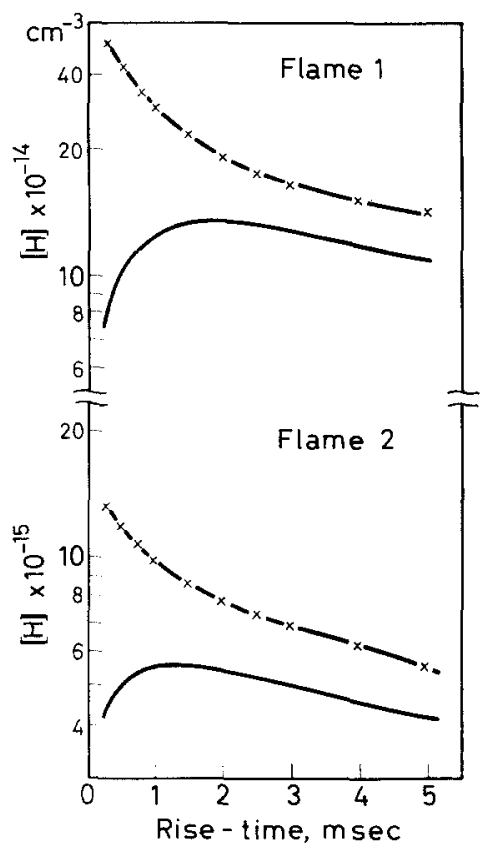

Figure 4

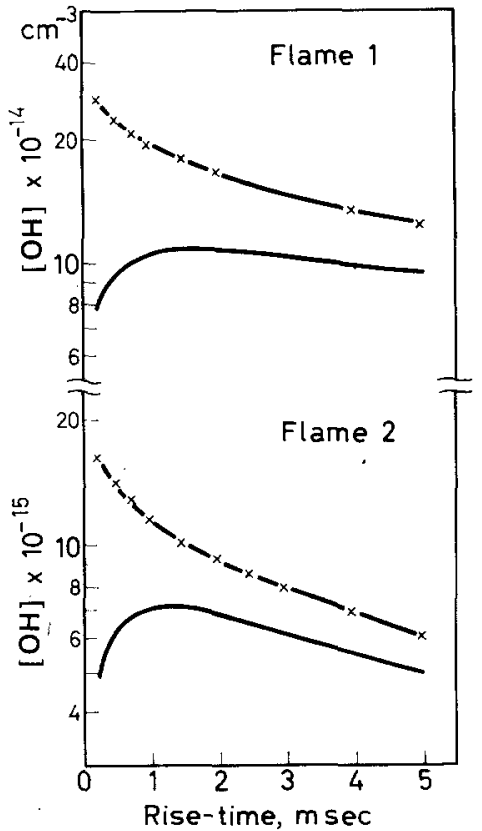

Figure 5

Figures 4 and 5. The calculated equilibrium $\mathrm{H}$ and $\mathrm{OH}$ concentrations and the actual $\mathrm{H}$ and $\mathrm{OH}$ concentrations $(\mathrm{x} \times \mathrm{x})$ in absolute measure have been plotted as a function of rise-time for flames Nos. 1 and 2, respectively

From this enthalpy value the chemical dissociation energy of $\mathrm{LiOH}$ was calculated to be $110 \pm \mathbf{5}$ $\mathrm{kcal} / \mathrm{mol}$. This value is consistent with the value of $102 \mathrm{kcal} / \mathrm{mol}$ found by H. SмIтH and T. M. SUGDEN ${ }^{18}$ and the value of $117 \mathrm{kcal} / \mathrm{mol}$ that can be calculated from data reported by $\mathrm{R}$. L. WILKINS et al. ${ }^{26}$.

The relative $H$ radical concentration as measured by the method described was plotted as a function of rise-time for flames Nos. 1 and 2 . These relative values could be converted into absolute values by adapting the (relative) measured $\mathrm{H}$ curve to the theoretical $\mathrm{H}$ curve calculated in absolute measure under conditions of full equilibrium (see Figure 4). The procedure of this adaptation will be described next.

Since the temperature continues to vary with height throughout the height-interval investigated, the calculated equilibrium $\mathrm{H}$ concentration various continuously too. On account of the relaxation in the establishment of the radical equilibrium, the actual $\mathrm{H}$ (and $\mathrm{OH}$ ) concentration curve will, in general, always lag behind the theoretical equilibrium curve. So, even in the right-hand tail of the curve where the decrease in $\mathrm{H}$ concentration approaches a fairly constant and moderate rate, the theoretical and experimental curves will never meet. The vertical separation between the tail of the experimental curve and that of the theoretical curve in Figure 4 can be determined in the following way. Shortly above the reaction zone the dissociating reactions are not important, so we may write instead of equation 10 , after dividing by $[\mathrm{H}]$,

$$
\Delta_{1}(\mathrm{H})=\left[-E B_{\mathrm{H}}[\mathrm{OH}]\right]_{1}
$$

in which $\Delta(\mathrm{H})$ stands for

$$
\left[A \mathrm{~d} \ln [\mathrm{H}] / \mathrm{d} t+C_{\mathrm{H}} \mathrm{d} T^{-1} / \mathrm{d} t\right]
$$

and the suffix ' 1 ' refers to a point near the reaction zone. For a point at the right-hand tail of the curve in Figure 4 (indicated by suffix ' 2 '), we can rearrange formula 10 by using

to yield

$$
\left[\mathrm{H}_{2} \mathrm{O}\right] / K_{\mathrm{e}}=[\mathrm{H}]_{\mathrm{eq}}[\mathrm{OH}]_{\mathrm{eq}}
$$

$$
\begin{aligned}
& \Delta_{2}(\mathrm{H}) \\
& =\left[-E B_{\mathrm{H}}[\mathrm{OH}]\left(1-[\mathrm{H}]_{\mathrm{el}}\right.\right. \\
& \left.\left.[\mathrm{OH}]_{\mathrm{eq}} /[\mathrm{H}][\mathrm{OH}]\right)\right]_{2}
\end{aligned}
$$


in which the suffix 'eq' indicates the equilibrium concentration calculated at the flame temperature at the point considered. It follows from equation 5 that at this point where the radical equilibria are nearly established and where also $\left[\mathrm{H}_{2}\right] \simeq\left[\mathrm{H}_{2}\right]_{\mathrm{eq}}, \quad[\mathrm{OH}]_{\mathrm{es}} /[\mathrm{OH}]$ equals $[\mathrm{H}]_{\mathrm{eq}} /[\mathrm{H}]$. Substituting this result in formula 15 and rearranging terms, we get

$$
\begin{array}{r}
\Delta_{2}(\mathrm{H})=\left[-E B_{\mathrm{H}}[\mathrm{OH}]\left(1+[\mathrm{H}]_{\mathrm{eq}} /[\mathrm{H}]\right)\right. \\
\left.\left(1-[\mathrm{H}]_{\mathrm{eq}} /[\mathrm{H}]\right)\right]_{2} \\
\ldots[16]
\end{array}
$$

Since $[\mathrm{H}]$ is not far from equilibrium, we may also write

$$
\Delta_{2}(\mathrm{H})=-2\left[E B_{\mathrm{H}}[\mathrm{OH}]\left(1-[\mathrm{H}]_{\mathrm{eq}} /[\mathrm{H}]\right)\right]_{2}
$$

After dividing both sides of equation 17 by those of equation 14 and assuming that $E$ has the same value at the two points considered, we get

$$
\left[\frac{[\mathrm{H}]_{\mathrm{eq}}}{[\mathrm{H}]}\right]_{2}=1-\frac{1}{2} \frac{\Delta_{2}(\mathrm{H})}{\Delta_{1}(\mathrm{H})} \frac{\left[B_{\mathrm{H}}[\mathrm{OH}]\right]_{1}}{\left[B_{\mathrm{H}}[\mathrm{OH}]\right]_{2}} \ldots
$$

The ratio $[\mathrm{OH}]_{1} /[\mathrm{OH}]_{2}$ and the values of $\mathrm{d} T^{-1} / \mathrm{d} t$ and of $\mathrm{d} \ln [\mathrm{H}] / \mathrm{d} t$ at points 1 and 2 can be derived directly from the (relative) experimental curves in Figures 4 and 5 . The factors $A, B_{\mathrm{H}}$ and $C_{\mathrm{H}}$ can be calculated from the known values of the relevant equilibrium constants $^{20}$, the calculated equilibrium concentrations of $\mathrm{H}_{2} \mathrm{O}$ and $\mathrm{CO}_{2}$ and the roughly estimated values of the actual $\mathrm{H}$ and $\mathrm{H}_{2}$ concentrations. The ratio $\left([\mathrm{H}]_{\mathrm{eq}} /[\mathrm{H}]\right)_{2}$, found from formula 18 is then accurate within five per cent. This ratio being known at one point of the flame, the position of the (relative) experimental curve with respect to the theoretical curve follows immediately. Since the theoretical curve is calculated in absolute measure, the actual [H] and $[\mathrm{OH}]$ values are now known in absolute measure too. It should be noted that in order to find the above ratio $\left([\mathrm{H}]_{\text {eq }} /[\mathrm{H}]\right)_{2}$, it is sufficient to suppose that the decay of $\mathrm{H}, \mathrm{OH}$ and $O$ radicals (caused by three-body recombinations) is not markedly dependent on temperature. The recombination rate constants are not required to be known absolutely.

Some additional calculations showed that in our flames the above assumptions were true within five per cent.

\section{The $\mathrm{OH}$ radical concentration}

These measurements were performed much more straightforwardly than for the $\mathrm{H}$ radicals, by measuring the strength of the absorption of the $\mathrm{OH}$ band at $3064 \AA$ (compare above). In order to convert absorption values into relative concentration values, the absorption factor was measured when the flame background radiation passed once, twice and three times, respectively, the (homogeneous and cylindrical) analysis flame at the same height. This calibrating measurement could be performed by switching additional mirrors into the light-path. The logarithm of the percentage transmission happened to be a linear function of the total length of the absorption path through the flame in the range investigated (see for theory references 27 and 28). This calibration curve was then used to convert absorption values, measured at different heights, into relative $\mathrm{OH}$ concentration values. One should note that, owing to non-thermal chemiluminescence effects, the U.v. OH emission is not a reliable measure for the $\mathrm{OH}$ concentration ${ }^{5}$.

The results obtained with flames Nos, 1 and 2 are plotted in Figure 5 together with the theoretical curves which were calculated under the assumption of complete flame gas equilibrium. By a procedure similar to that used with the $\mathrm{H}$ curves in Figure 4, it was possible to fix the position of the experimental $\mathrm{OH}$ curve with respect to the theoretical curve, so that the $\mathrm{OH}$ concentrations actually found could be expressed in absolute values. With flame No. 3 no reliable results were obtained.

\section{Results and Discussion}

It is impossible to integrate equations 10 and 11 in a closed form. Therefore we plotted the value of

$$
\left\{-A \mathrm{~d}[\mathrm{H}] / \mathrm{d} t-C_{\mathrm{H}}[\mathrm{H}] \mathrm{d} T^{-1} / \mathrm{d} t\right\}
$$

against the corresponding value of $\left\{[\mathrm{H}][\mathrm{OH}]-\left[\mathrm{H}_{2} \mathrm{O}\right] / K_{2}\right\} B_{\mathrm{H}}$ at several points in the flame. The results are presented in Figure 6 for flames Nos. 1 and 2 . The procedure for finding the values of the factors involved in 


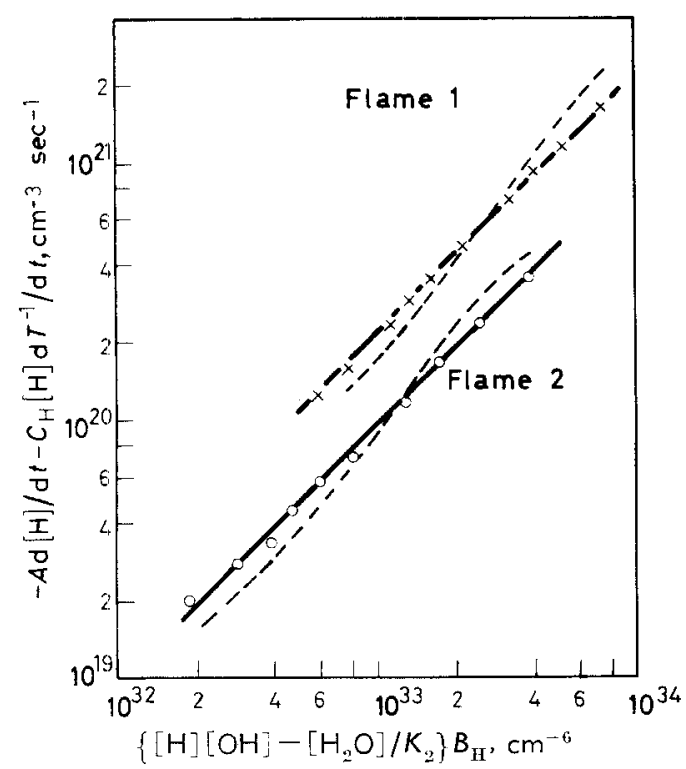

Figure 6. Decay rate of $\mathrm{H}$ radical concentration in relation lo excess values of $\mathrm{H}$ and. $\mathrm{OH}$ concentrations in flames Nos. 1 and 2, respectively. Values of $\left\{-A \mathrm{~d}[\mathrm{H}] / \mathrm{d} t-C_{\mathrm{H}}[\mathrm{H}] \mathrm{d} T^{-1} / \mathrm{d} t\right\}$ found from the experimints at different heights in the flame are plotted using double logarithms as functions of $\left\{\left[\mathrm{H}_{\mathrm{i}} \mathrm{OH}\right]-\left[\mathrm{H}_{2} \mathrm{O}\right] / \mathrm{K}_{2}\right\} B_{\mathrm{H}}$. As predicted by theory the points appear to lie on a straight line with a slope of $45^{\circ}$. When neglecting the influence of the variation of flame temperature as a function of height in the flame (described by the term $C_{\mathrm{II}}[\mathrm{H}] \mathrm{d} T^{-1} / \mathrm{d} t$ ), the points are found to lie on the dotted curve and do not appear to fit a straight line

this plot was as follows.

From the experiments the $\mathrm{H}$ and $\mathrm{OH}$ concentrations are known in absolute measure (see above). The variations of the $\mathrm{H}_{2} \mathrm{O}$ and $\mathrm{CO}_{2}$ concentrations in relative measure as a result of the relaxation in the equilibration of reactions I, II, III and IV are calculated to be negligible (less than 0.1 per cent), and hence the actual values of these concentrations may be assumed equal to the calculated equilibrium values given in Figure 3. The actual $\mathrm{H}_{2}$ conceniration at each point in the flame can be derived from the mass-balance for hydrogen

$$
[\mathrm{H}]+2\left[\mathrm{H}_{22}\right]+2\left[\mathrm{H}_{2} \mathrm{O}\right]+[\mathrm{OH}]=\text { constant }
$$

taking into account equation $\mathbf{5}$. Here the variaion of $\mathrm{H}_{2} \mathrm{O}$ concentration in absolute amount sannot be disregarded, however.

The values of these concentrations and the ?quilibrium constants now being known, the quantities $A, B_{\mathrm{H}}, B_{\mathrm{OH}}, C_{\mathrm{H}}$ and $C_{\mathrm{OH}}$ can be calculated at each point of the flame.

The values of $\mathrm{d}[\mathrm{H}] / \mathrm{d} t$ and $\mathrm{d}[\mathrm{OH}] / \mathrm{d} t$ at each point in the flame were determined graphically from the curves shown in Figures 4 and 5. It appears that the terms $k_{1} K_{5}[\mathrm{M}]\left[\mathrm{H}_{2}\right] /\left[\mathrm{H}_{2} \mathrm{O}\right]$ and $k_{4}[\mathrm{M}] K_{5} K_{7}\left[\mathrm{O}_{2}\right] / K_{6}\left[\mathrm{H}_{2} \mathrm{O}\right]$ in the factor $E$ may be neglected in comparison with $k_{2}[\mathrm{M}]$ in the flames considered, since $(i) k_{1}[\mathrm{M}] / k_{2}[\mathrm{M}]$ is of order $0.04^{21,22}$, (ii) $K_{5}\left[\mathrm{H}_{2}\right] /\left[\mathrm{H}_{2} \mathrm{O}\right]$ ranges from $0 \cdot 1$ to 1 , (iii) $k_{4}[\mathrm{M}] / k_{2}[\mathrm{M}]$ is of order $0 \cdot 03^{3,24}$, (iv) $K_{5} K_{7}\left[\mathrm{O}_{2}\right] / K_{6}\left[\mathrm{H}_{2} \mathrm{O}\right]$ ranges from 0.05 to 0.5 . This implies that reactions $I$ and $I V$ are not important in our flames. The term $K_{5}\left[\mathrm{CO}_{2}\right] / K_{6} K_{8}\left[\mathrm{H}_{2} \mathrm{O}\right]$ turns out to be constant within five per cent in the temperature range considered, due to the weak temperature dependence of $K_{5} / K_{6} K_{8}$ (the algebraic sum of the corresponding reaction enthalpies being about $-3 \mathrm{kcal} / \mathrm{mol}$ ).

If one neglects the temperature dependence of the recombination rate constants $k_{2}$ and $k_{s}$, which seems quite reasonable, the factor $E$ is expected to be constant and the experimental points should lie on a straight line with a slope of $45^{\circ}$. It appears necessary to account for the variation of temperature with height (i.e. to consider the contribution of the term $C_{\mathrm{Ir}}[\mathrm{H}] \mathrm{d} T^{-1} / \mathrm{d} t$ to the ordinate values) in plotting Figure 6, as may be seen from the deviation of the dotted curve from the straight line (see caption).

From the intercept of these curves one finds $E$, which yields the binary rate constant $k_{2}[\mathrm{M}]$ if the rate constant $k_{3}$ [M] is known. The latter rate constant was derived indirectly from the initial rise in temperature in a carbon monoxidenitrogen-oxygen flame, due to the heat evolved in the recombination reaction $\mathrm{CO}+\mathrm{O} \rightarrow \mathrm{CO}_{n}$, and amounts to $3 \times 10^{-15} \mathrm{~cm}^{3} \mathrm{sec}^{-1}$ at $2050^{\circ} \mathrm{K}^{17}$. This value is reasonably close to the value $6 \times 10^{-1.5} \mathrm{~cm}^{3} \mathrm{sec}^{-1}$ calculated from

$$
k_{3}[\mathrm{M}]=10^{10} \exp (-4000 / R T) \mathrm{cm}^{3} \mathrm{~mol}^{-1} \mathrm{sec}^{-1}
$$

which was found in molecular beam experiments at $350^{\circ}$ to $550^{\circ} \mathrm{K}^{25}$. This agreement is sufficient for the determination of $k_{2}$ [M] in the flames considered, since the relative contribution of the term containing $k_{3}[\mathrm{M}]$ amounts to about ten per cent. From our measurements we obtain 
with flame No. 1

$$
k_{2}[\mathrm{M}]=(17 \pm 3) \times 10^{-14} \mathrm{~cm}^{3} \mathrm{sec}^{-1}
$$

and with flame No. 2

$$
k_{2}[\mathrm{M}]=(9 \pm 2) \times 10^{-14} \mathrm{~cm}^{3} \mathrm{sec}^{-1}
$$

No explanation can be given for the difference between these two values. The temperature difference of flame No. $1\left( \pm 2250^{\circ} \mathrm{K}\right)$ and flame No. $2\left( \pm 2350^{\circ} \mathrm{K}\right)$ seems to be too small to be important. The influence of the third body, $M$, cannot account for this discrepancy, since (i) the concentration of each of the major species, $\mathrm{N}_{2}$ and $\mathrm{H}_{2} \mathrm{O}$, is the same (within five per cent) in both flames; (ii) the difference of a factor 1.5 in the $\mathrm{CO}_{2}$ concentration could only be important if the collisional cross section of $\mathrm{CO}_{2}$ as a third body were much higher (by about 100 times) than the cross section of $\mathrm{N}_{2}$ or $\mathrm{H}_{2} \mathrm{O}$. This seems very unlikely; (iii) the other flame molecules are of minor importance as a result of their low concentration. Nevertheless the orders of magnitude of the values found by us are consistent with the widely varying values reported in the literature (1,3,22,23. $^{1}$.

The internal consistency of the measurements

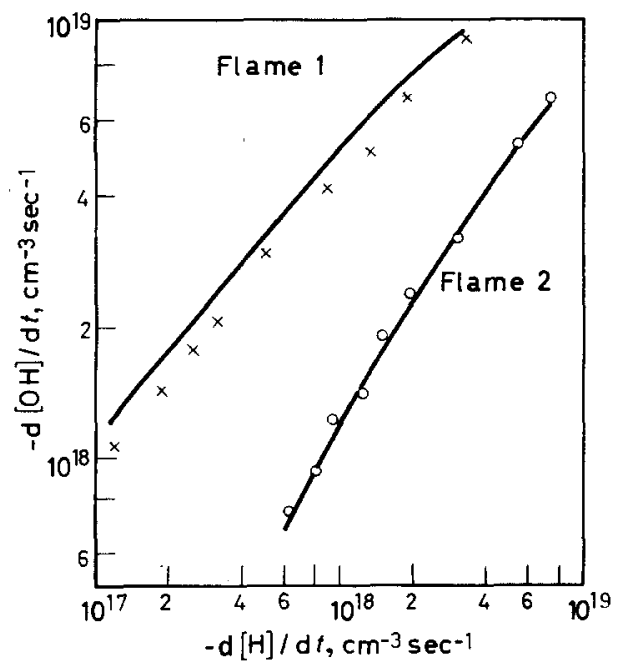

Figure 7. Decay rate of $\mathrm{OH}$ radicals against the decay rate of $\mathrm{H}$ radicals. The relation predicted by theory is shown by the curves drawn; the experimental values are represented by $\mathrm{xxx}$ and ooo for flames Nos. 1 and 2 , respectively of $\mathrm{d}[\mathrm{OH}] / \mathrm{d} t$ with those of $\mathrm{d}[\mathrm{H}] / \mathrm{d} t$ is shown in Figure 7. These curves show the relation between $\mathrm{d}[\mathrm{OH}] / \mathrm{d} t$ and $\mathrm{d}[\mathrm{H}] / \mathrm{d} t$, calculated from formula 12 , the factors $A, B_{\mathrm{H}}, B_{\mathrm{OH}}, C_{\mathrm{g}}$ and $C_{\mathrm{OH}}$ being known. Reasonable agreement exists between the experimental points and the theoretical curves. From this agreement it also follows that an analysis of the $\mathrm{OH}$ measurements must yield the same value for the factor $E$ in formula 11 as was found from the $\mathrm{H}$ measurements.

\section{References}

1 Rosenfeld, J. L. J. and Sugdes, T. M. Combustion $\&$ Flame, 1964, 8, 44

2 Reid, R. and Wheeler, R. J. phys. Chem. 1961, 65, 527

3 Westenberg, A. A. and Favin, S. Ninth Symposium (International) on Combustion, p 785. Academic Press: New York, 1963

4 Alkemade, C. Th. J. Proceedings of the Tenth International Colloquium on Spectroscopy, p 143. Spartan Books: Washington, 1963

5 Zeegers, P. J. Th. and Alkmade, C. Th. J. Tenth Symposium (International) on Combustion, p 33. Combustion Institute: Pittsburgh, 1965

'Kaskan, W. E. J. chem. Phys. 1959, 31, 944

i Hollander, TJ., KalfF, P. J. and Alkemade, C. TH. J. J, chem. Phys. 1963, 39, 2558

8 Schofield, K, and Sugori, T. M. Tenth Symposium (International) on Combustion, p 589. Combustion Institute: Pittsburgh, 1965

9 Alkemade, C. Th. J. Thesis Utrecht, 1954

10 Hollander, TJ. Thesis Utrecht, 1964

11 Snelleman, W. Thesis Utrecht, 1965

12 Padley, P. J. and Sugdex, T. M. Proc. Roy. Soc. $A, 1958,248,248$

13 Kaskan, W. E. Combustion \& Flame, 1958, 2, 229

14 Fenimore, C. P. and Jones, G. W. Tenth Symposium (International) on Combustion, p 489. Combustion Institute: Pittsburgh, 1965

15 Dixon-Lewis, G., Sutton, M. M. and Williams, A. Tenth Symposium (International) on Combus tion, $\mathrm{p}$ 495. Combustion Institute: Pittsburgh, 1965

16 Herrmans, R. and Alkmmade, C. Тh. J. Flammenphotometrie, 2nd ed. Springer: Göttingen, 1960; translated into English by P. T. GILBERT, Interscience: New York, 1963

17 ZneGers, P. J. TH. Thesis Utrecht. To be published

18 Smith, H. and Sugden, T. M. Proc. Roy. Soc, A, 1953, 219, 204

19 James, C. G. and Sugden, T. M. Proc. Roy. Soc. $A, 1955,227,312$

20 Gaydon, A. G. and Wolfhard, H. G. Flames, 2nd ed. Chapman \& Hall: London, 1960 
21 Bulewicz, E. M. and Sugden, T. M. Trans. Faraday Soc. 1958, 54, 1855

22 Dixon-lewis, G., Sutron, M. M. and Williams, A. Disc. Faraday Soc. 1960, 33, 205

23 McAndrew, R. and Wheeler, R. J. phys. Chem. 1962, 66., 229

24 Risik, J. P., Knight, H. T. and Duff, R. E. J. chem. Phys. 1961, 34, 1942
25 Mahan, B. H. and Solo, R. B. J. Chem. Phys. $1962,37,2669$

26 Wilkins, R. L., Lodwig, R. M. and Greene, S. A. Ninth Symposium (International) on Combustion, p 560. Academic Press: New York, 1963

27 Plass, G. N. Applied Optics, 1965, 4, 69

28 Plass, G. N. Applied Optics, 1965, 4, 161 